\title{
HCV elimination: breaking down the barriers to prison based care
}

\author{
Timothy Papaluca ${ }^{1,2}$, Alexander Thompson ${ }^{1,2}$ \\ 'Department of Gastroenterology, St Vincent's Hospital, Melbourne 3065, Australia. \\ ${ }^{2}$ School of Medicine, Dentistry and Health Sciences, University of Melbourne, Melbourne 3052, Australia.
}

Correspondence to: Dr. Alexander Thompson, Department of Gastroenterology, St Vincent's Hospital, Melbourne 3065, Australia. E-mail: alexander.THOMPSON@svha.org.au

How to cite this article: Papaluca T, Thompson A. HCV elimination: breaking down the barriers to prison based care. Hepatoma Res 2018;4:64. http://dx.doi.org/10.20517/2394-5079.2018.53

Received: 6 May 2018 First Decision: 9 Jul 2018 Revised: 16 Jul 2018 Accepted: 25 Jul 2018 Published: 17 Oct 2018

Science Editor: Guang-Wen Cao Copy Editor: Cui Yu Production Editor: Zhong-Yu Guo

\begin{abstract}
Hepatitis $\mathrm{C}$ virus (HCV) remains a major public health threat worldwide, responsible for 500,000 deaths annually; hepatocellular carcinoma (HCC) remains one of the major causes of HCV-related mortality. The global prevalence of $\mathrm{HCV}$ is approximately $1.0 \%$, and in developed countries, injecting drug use continues to be the primary risk factor in incident cases. Targeted treatment of people who inject drugs (PWID) is important for achieving the WHO goals of eliminating viral hepatitis, which will have a significant impact on reducing HCC rates. Due to the close relationship between injecting drug use, incarceration and chronic HCV, the prevalence of HCV is up to 40 times greater within correctional facilities compared with the community. However, very few prisoners are treated for HCV while incarcerated. This is a result of financial, logistical and prisoner barriers to HCV care within correctional facilities. In the era of direct acting antiviral (DAA) therapy which is highly efficacious, time-efficient and safe, modelling studies have identified the benefit of increasing HCV treatment uptake amongst PWIDs to reduce community prevalence via treatment-as-prevention. Despite this, there are few real-world data evaluating DAA therapy within prison settings. In this article, we review the barriers to HCV care within prison systems, the outcomes of traditional HCV treatment programs within prisons and emerging data regarding the benefit of DAA therapy within correctional facilities. We present the mathematical modelling regarding the impact of treatment as prevention amongst PWIDs to eliminate HCV as a public health threat and how the prison fits into this paradigm.
\end{abstract}

Keywords: Hepatitis C virus, people who inject drugs, prisoner, elimination, direct acting antiviral

\section{INTRODUCTION}

Hepatitis $\mathrm{C}$ virus (HCV) is a prominent public health issue worldwide. It is estimated that there are over

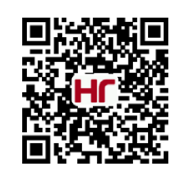


70 million people chronically infected with HCV, with a global prevalence of $1.0 \%{ }^{[1]}$. Over time, HCV mediated inflammation leads to the development of liver fibrosis, and can subsequently cause decompensated cirrhosis and hepatocellular carcinoma (HCC) $)^{[2,3]}$. HCV accounts for approximately 500,000 deaths per year globally and remains the leading indication for orthotropic liver transplantation in the western world $\mathrm{d}^{[4,5]}$. Viral hepatitis, including HCV, is responsible for $>60 \%$ of incident HCCs and was the 7 th leading cause of death globally ${ }^{[6,7]}$.

The advent of direct acting antiviral (DAA) therapy has revolutionised HCV treatment. HCV DAA therapy is highly efficacious, yet simple, safe and short in duration in relation to pegylated interferon- $\alpha$ and ribavirin (PEG RBV) which had significant toxicity and poor efficacy ${ }^{[8]}$. The introduction of DAA therapy led the World Health Organisation (WHO) to propose targets for the reduction of HCV incidence and mortality of $80 \%$ and $65 \%$ respectively by $2030^{[\rho]}$. In developed countries, injecting drug use continues to be the primary risk factor for acquiring HCV, accounting for the majority of incident cases ${ }^{[10,11]}$. As such, treatments scale up amongst people who inject drugs (PWID) are key to achieving these elimination targets, which are supported by multiple HCV modelling studies ${ }^{[12]}$. PWIDs however are often marginalised and historically it's been difficult for them to be engaged in care.

There are an estimated 10 million prisoners worldwide, with over 2 million incarcerated in the USA alone ${ }^{[13,14]}$. This population has an extremely high prevalence of chronic HCV infection. Conservative estimates suggest there are approximately 1.5 million prisoners living with HCV at any given time ${ }^{[15]}$. This reflects the close association between PWID, incarceration and HCV due to the criminalisation of injecting drug use. Incarceration itself is an independent risk factor for HCV infection ${ }^{[16]}$ and over $50 \%$ of PWIDs will spend some time in prison ${ }^{[17]}$. Recent modelling has demonstrated that to achieve the proposed WHO elimination targets, HCV treatments must be significantly scaled up amongst PWIDs to influence reductions in HCV incidence and prevalence ${ }^{[12]}$. The prison system is an ideal setting for such public health initiatives given these characteristics and can play a key role in elimination efforts. However, to date there has been limited prison based HCV treatment in the setting of prisoner, organisational and funding/policy barriers. In 2015, a survey conducted in 49 of the 50 State Department of Corrections in the US, responsible for the care of $1,348,716$ prisoners, estimated that $<1 \%$ of prisoners with chronic HCV infection were receiving treatment ${ }^{[1]}$.

This article explores the prevalence of HCV within correctional facilities, presents the existing literature describing the efficacy of HCV treatment, and discusses the barriers to implementation and upscaling of HCV treatment in prisons. Finally, the opportunity for correctional HCV treatment programs to support HCV eliminations goals in the era of DAA therapy is discussed.

\section{HCV PREVALENCE GLOBALLY, IN PWIDS AND CORRECTIONAL FACILITIES WORLDWIDE}

Recent systematic reviews have estimated that HCV prevalence is approximately $1.0 \%$ worldwide, with 71 million people affected ${ }^{[1]}$. Countries with high HCV viraemia prevalence include those found in Northern Africa, the Middle East and Central Asia, where prevalence may exceed 3\%. A systematic review investigating HCV prevalence amongst PWIDs estimated that worldwide, 67\% are affected by chronic HCV. Thirty eight of 79 countries, where data regarding HCV prevalence are available, have a HCV prevalence amongst their PWIDs of greater than $60 \%$ - these included China (67\%), Russia (72.5\%) and the USA (73.4\%).

Due to the close association between injecting drug use and incarceration, the high prevalence of HCV within the PWID community has created the epidemic in correctional facilities worldwide. Studies demonstrate that 56\%-90\% of PWID will spend time in prison during their lifetime and HCV prevalence is up to 40 times higher amongst incarcerated populations when compared with the community ${ }^{[19]}$. A recent systemic review assessed HCV prevalence amongst incarcerated populations ${ }^{[15]}$. The midpoint HCV prevalence was $15.1 \%$, equating to $1,546,500$ of prisoners globally being affected by $\mathrm{HCV}^{[13]}$, and prevalence exceeded $10 \%$ in six of nine regions worldwide. A second review estimated anti-HCV prevalence at $26 \%$ amongst prisoners, and $64 \%$ amongst those 
Table 1. Barriers to prison-based HCV treatment and potential solutions

\begin{tabular}{|c|c|}
\hline Barriers & Solutions \\
\hline $\begin{array}{l}\text { System/prison factors } \\
\text { Low HCV screening rates } \\
\text { Short prison sentences } \\
\text { Low prioritisation of a chronic disease } \\
\text { Frequent interprison transfers interrupting treatment } \\
\text { Limited harm reduction strategies } \\
\text { High rates of dropout in HCV care cascade relating to missed opportunity in: } \\
\text { Confirming HCV diagnosis } \\
\text { Referring for assessment } \\
\text { Commencing therapy }\end{array}$ & $\begin{array}{l}\text { System/prison factors } \\
\text { HCV testing for all detainees on incarceration } \\
\text { Increase number of DAA prescribers to facilitate local } \\
\text { treatment } \\
\text { Promote jurisdiction-wide care to manage frequent prisoner } \\
\text { transfer } \\
\text { Increase access to harm reduction strategies }\end{array}$ \\
\hline $\begin{array}{l}\text { Prisoner factors } \\
\text { Prisoner attitudes and knowledge regarding: } \\
\text { HCV screening - including fear of diagnosis, difficulty with venepuncture } \\
\text { HCV therapies - side effects, tolerability, efficacy } \\
\text { Perceived stigma of HCV treatment } \\
\text { Motivation }\end{array}$ & $\begin{array}{l}\text { Prisoner factors } \\
\text { Promote prisoner group education to manage deficiencies in } \\
\text { HCV-related knowledge }\end{array}$ \\
\hline $\begin{array}{l}\text { Economic factors } \\
\text { High list price of HCV DAA therapies } \\
\text { Limited prison healthcare resources }\end{array}$ & $\begin{array}{l}\text { Economic factors } \\
\text { Validation of simplified methods of fibrosis determination (ie } \\
\text { APRI) to minimize the need for FibroScan }\end{array}$ \\
\hline $\begin{array}{l}\text { Treatment factors } \\
\text { Toxicity of historical PEG RBV therapy } \\
\text { Duration of treatment } \\
\text { Specialist access } \\
\text { Knowledge gap among prison medical, nursing and security staff regarding } \\
\text { current HCV cascade of care }\end{array}$ & $\begin{array}{l}\text { Treatment factors } \\
\text { Utilization of short duration, all oral DAA therapy for HCV } \\
\text { Implementation of facilities including telehealth to address } \\
\text { limited access to specialist care } \\
\text { Education programs for prison healthcare staff regarding HCV } \\
\text { diagnosis and treatment }\end{array}$ \\
\hline
\end{tabular}

DAA: direct acting antivirals; HCV: hepatitis C virus; PEG RBV: pegylated interferon \& ribavirin; APRI: aspartate aminotransferase to platelet ratio index

prisoners who were identified as a PWID ${ }^{[20]}$. Significant heterogeneity between different regions was observed [Australasia (35\%), Central Asia (38\%) and Latin America (4.7\%) ${ }^{[15,20]}$.

\section{HISTORIC HCV TREATMENT AND BARRIERS}

Less than one percent of eligible prisoners living with HCV are currently treated while incarcerated ${ }^{[21,22]}$. HCV management within the prison relies on screening, clinical and laboratory assessment, specialist assessment, treatment access and confirmation of cure. At each step, there are organisational and financial barriers which have traditionally limited the number of prison based treatment [Table 1].

\section{Screening and assessment}

Despite WHO recommendations that all prisoners should be screened for $\mathrm{HCV}^{[23]}$, practice varies greatly worldwide. Only 34\% (10/29) of European countries and 20\% of the United States jurisdictions report established HCV screening protocols ${ }^{[24,25]}$. Furthermore, where HCV screening is available, access to screening may be restricted to prisoners with a risk factor for HCV, such as PWID status or deranged liver biochemistry ${ }^{[26]}$, despite the fact that incarceration itself is an independent risk factor for HCV infection ${ }^{[16]}$. Uptake of screening may be variable. A Canadian study identified that only $30 \%$ of prisoners were tested while incarcerated although universal opt-in screening being policy, and HCV screening across 21 English prisons reached less than $3 \%$ of prisoners ${ }^{[27,28]}$. The cause of this is likely multi-factorial, including the cost of HCV diagnostics, the prioritisation of preventative health care within a prison budget, prisoner movement within prison systems limiting health centre access, and the stigma that can be associated with HCV testing ${ }^{[29,30]}$. Screening uptake may also be impeded by prisoner factors including lack of knowledge about HCV or fear of diagnosis ${ }^{[31]}$. PWIDs can have very difficult venous access resulting in fear of venepuncture - one prison based study utilised dried blood spot testing for HCV screening and noted a $12.2 \%$ increase in uptake ${ }^{[32]}$. Barriers to HCV screening may be best addressed by implementing universal opt-out practices in all correction facilities worldwide to increase diagnosis rates and treatment throughput ${ }^{[2]}$.

Seropositive prisoners require further diagnostic testing to confirm chronic infection and stage liver fibrosis. 
In one study only $62 \%(n=1490 / 2413)$ of anti-HCV positive prisoners had a HCV PCR test performed during their incarceration ${ }^{[28]}$. Liver imaging and/or elastography can be challenging. More than $85 \%$ of English prisons currently transfer prisoners to an external health centre for ultrasound or liver stiffness measurements (FibroScan) ${ }^{[33]}$.

\section{Treatment}

Even when screening is protocolised ${ }^{[2]}$, linkage to HCV treatment is often low. In Wisconsin, USA, only $18 \%$ of 3126 prisoners affected by chronic HCV were assessed for treatment whilst incarcerated ${ }^{[34]}$. The need for specialist review can cause considerable delay due to inadequate medical and nursing resourcing on site ${ }^{[30,35]}$, a delay which may be exaggerated by the need for transfer to public hospital outpatient department ${ }^{[33]}$. Geographical isolation also contributes to delayed assessments. These delays are at odds with the short average prison sentence and frequent prisoner turnover. Prior to the recent introduction of DAAs, the treatment consisted of PEG RBV which was associated with significant side effects and was poorly tolerated. As such many prisoners were ineligible, intolerant or unwilling to undertake HCV therapy ${ }^{[35,36]}$. Psychiatric comorbidity was a particular issue, affecting more than $50 \%$ of prison populations, and affecting eligibility for treatment ${ }^{[37,38]}$. Finally, interprison transfers, frequent in correctional facility networks, can cause disruption and cessation of treatment where treatment programs are siloed to one facility ${ }^{[31,35]}$. In the era of well-tolerated and highly efficacious treatments, jurisdiction-wide, coordinated efforts are necessary to develop models of care to overcome these barriers.

The high list price of HCV DAA therapy may also be prohibitive for correctional services due to limitations in fixed healthcare budgets. DAA HCV therapy is expensive. The wholesale price of therapy ranges from $\$ 54,600$ to $\$ 147,000$ depending on the regimen selected ${ }^{[39]}$. Despite this high cost however, due to the much less resource intensive on-treatment monitoring, and the improved efficacy compared with PEG RBV, the price per sustained virological response (SVR) achieved by DAA therapy is cheaper than for PEG RBV ${ }^{[39]}$.

\section{TREATMENT AS PREVENTION MODELLING, COST EFFECTIVENESS OF PWID TREATMENTS}

PWIDs present unique challenges regarding HCV care in the community. A large proportion of PWIDs remain undiagnosed due to limitations in access or availability of appropriate diagnostic services ${ }^{[40]}$. Diagnosis rates in the general population in Western Countries vary between 15\%-86\% in the literature, and the diagnosis rate in active PWID is low ${ }^{[41]}$. Once diagnosed, PWIDs are less likely to access medical care compared with their non PWID counterparts, preventing them from accessing effective treatments ${ }^{[42]}$. Even in the case of successful linkage to physician care, in the pre-DAA era, less than $20 \%$ were commenced on treatment due to multiple patient and physician factors ${ }^{[40]}$.

The PWID population therefore experiences difficulties progressing though the HCV care cascade. Irrespective of these challenges, to achieve the WHO elimination targets ${ }^{[\rho]}$, there needs to be a concerted effort to increase treatments uptake amongst this key population ${ }^{[43]}$. Multiple mathematical modelling studies have now clearly demonstrated a benefit at a population level of scaling up HCV treatment amongst PWIDs who contribute most heavily to incidence and prevalence. This notion, referred to as "treatment-as-prevention" (TAsP) not only treats the individuals but reduces incident infections via interrupting transmission ${ }^{[4]}$. Targeted treatment of PWID is therefore a priority for eliminating HCV as a public health threat.

\section{Modelling studies of treating PWID in community}

Australia has a policy of universal DAA access, irrespectively of their underlying degree of fibrosis or PWID status, and has been considered in a mathematical modelling study to assess the impact of treatment scale up amongst PWIDs ${ }^{[12]}$. The Australian model accounted for transmission, reinfection, treatment associated costs and progression of liver disease. It was determined that both the incidence and mortality targets could be achieved by 2030 by delivering 4725 treatments/year to PWIDs, equating to 59 out of each 1000 current 
PWIDs in Australia. This strategy resulted in a spend of \$A3.895 billion over 15 years compared with inaction, but resulted in 132,000 quality adjusted life years (QALYs) gained. Using a willingness to pay (WTP) threshold of \$AUD50,000 per QALY, this was cost effective with an incremental cost-effectiveness ratio of \$A29,614 per QALY gained. The modelling is reproduced in Figure 1 which demonstrates the rapid reduction in incidence and prevalence utilising this method compared treating those with established liver disease where reductions are only modest [Figure 1].

Iceland also has a policy of universal DAA access ${ }^{[45]}$. Iceland was also evaluated in an mathematical model to establish key targets required to achieve the elimination objectives as stipulated by $\mathrm{WHO}^{[9]}$. Iceland has a population of 332,000, of which 1300 are estimated to be living with HCV. The modelling determined that if DAA therapy was provided at current treatment levels, accompanied by unchanged HCV testing rates amongst the PWID population, incidence would decrease by $72 \%$ by 2030 , yet still short of the WHO target. Comparatively, elimination could be achieved by 2030, 2025 or 2020, if 55/1000, 75/1000 or 188/1000 of the country's current PWIDs underwent HCV treatment per year. In all scenarios modelled, the elimination targets were achieved only where treatment was scaled up amongst PWIDs. The researchers did acknowledge that to satisfy this model, an increase in HCV diagnosis amongst Icelandic PWIDs or a $20 \%$ increase in harm reduction services is required.

A modelling study regarding PWIDs in Montreal, Canada identified the importance of early HCV diagnosis and prompted linkage to care ${ }^{[46]}$. Montreal has 4000 PWIDs who are variably involved in HCV care. The researchers established key variables in their mathematical model including the interval between acquisition and diagnosis, time to linkage to care, lost to follow up rates, referral-to-treatment conversion and the efficacy of treatment, defined as likelihood of SVR12. The modelling demonstrated that the greatest incidence and prevalence reductions of $76 \%$ and $4.3 / 100$ person years over 10 years respectively were achieved by maximising treatments delivered to PWIDs, irrespective of fibrosis stage, and by improving the cascade of care throughput. Comparatively, where treatments were delivered only to PWID with hepatic fibrosis or cirrhosis, incidence and prevalence estimates were only modestly reduced as TAsP was not achieved. The TAsP principle is supported by an alternate study ${ }^{[47]}$ which demonstrated that treating 120/1000 PWIDs per year in the USA, in a climate of $60 \% \mathrm{HCV}$ prevalence amongst PWIDs, would achieve elimination within 10 years.

HCV TAsP is also cost-effective. Martin et al ${ }^{[48]}$ utilised a mathematic model which evaluated the impact of HCV therapy delivered to either PWID, ex-PWID or never-PWID in a setting of varying HCV prevalences. The model considered the effect on transmission, interrupting liver disease progression and reinfection after SVR12. In a climate of $40 \%$ chronic HCV infection amongst PWIDs, it was most cost effective to provide HCV therapy to PWIDs with moderate fibrosis, followed by PWIDs with mild fibrosis. Both scenarios were more cost effective than treating ex- or never-PWIDs due to the prevention of incident infections via transmission. Treating PWIDs with moderate and mild fibrosis conferred the greatest net monetary benefit of $£ 60,640$ and $£ 59,258$ respectively (where chronic HCV infection was $20 \%$ amongst PWIDs) by minimising future medical expenditures and gaining QALYs. The cost effectiveness of this approach is in contrast to policies which limit the use of DAAs to patients with advanced fibrosis or cirrhosis only, including in the USA, and will result in higher ongoing HCV related costs despite the failure to control the HCV epidemic ${ }^{[49]}$.

\section{Modelling studies of treating PWID in prison}

The role of prison-based HCV treatment programs to reduce disease prevalence within the broader community has been demonstrated with Scottish data ${ }^{[50]}$. The model determined $27.7 \%$ of incident HCV infections in Scotland related to incarceration, particularly related to the heightened risk of transmission immediately postrelease. Via treatment scale up that would reach $80 \%$ of all HCV infected PWIDs with a sentence duration of > 16 weeks, this intervention alone could reduce Scotland's incidence and prevalence by $45.6 \%$ and $45.5 \%$ respectively by 2030, highlighting the key role of prison based programs to achieve elimination. 


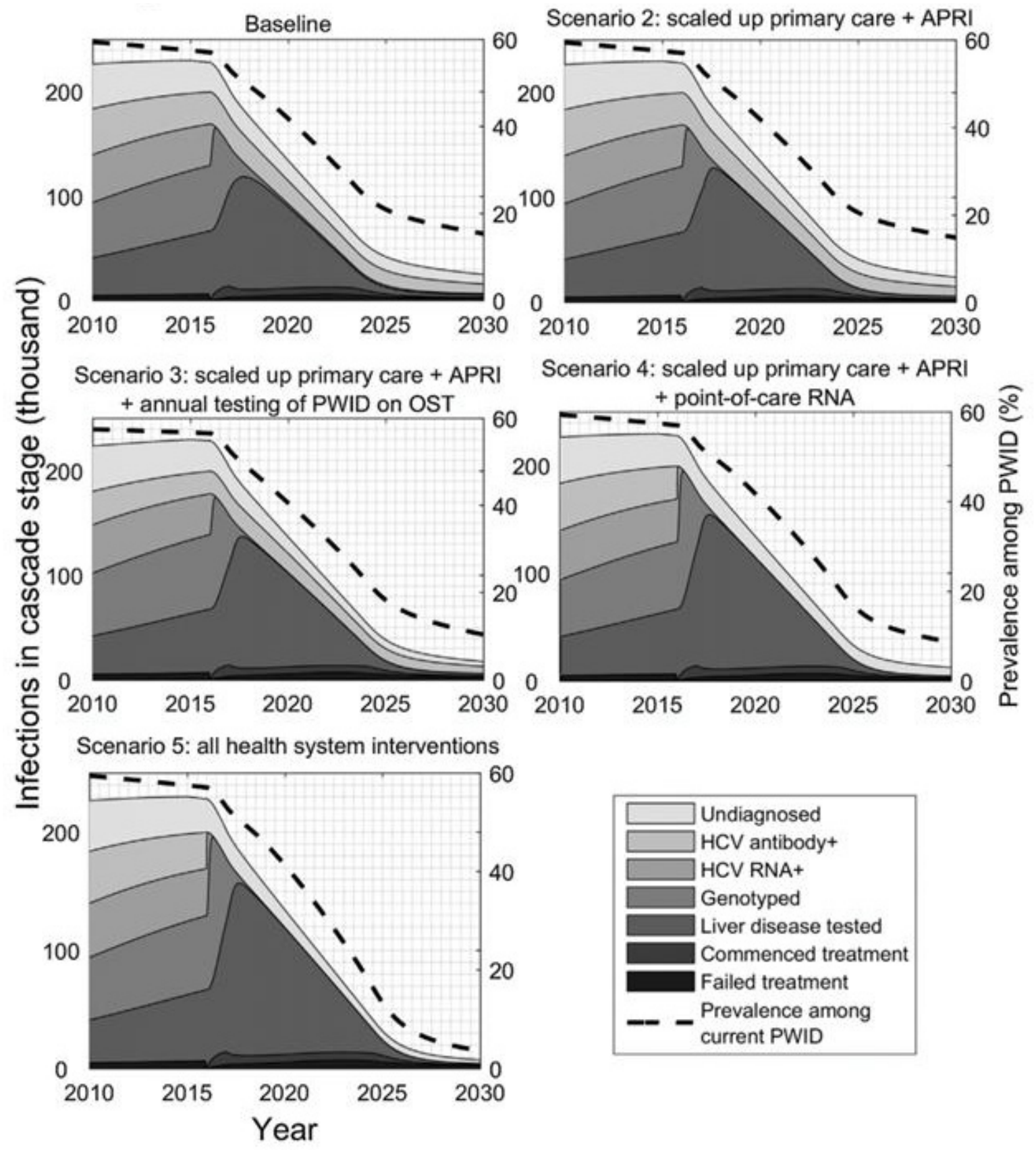

Figure 1. Australian HCV infections in various cascade stages; projected outcomes 2016-2030 under different scenarios, reproduced with permission from Scott et al ${ }^{[12]}$. HCV: hepatitis C virus; OST: opiate substitution therapy; PWID: people who inject drugs; APRI: aspartate aminotransferase to platelet ratio index

Modelling specifically pertaining to the prison system in England demonstrated that in the era of HCV DAA regimens of 8-12 weeks duration for all genotypes, by doubling HCV testing rates on prison receptions (currently at $6 \%$ with current UK opt in screening practices) and ensuring 10\% of prisoners referred with HCV are treated, prison based DAA treatments are likely to be $99 \%$ cost effective under a $£ 13,000$ WTP per QALY gained $^{[51]}$.

\section{CURRENT HCV TREATMENT PROGRAMS WITHIN PRISONS}

There are limited data describing HCV treatment in the prison setting, particularly in the DAA era [Table 2] ${ }^{[52-61]}$. 
Table 2. Outcomes of prison based HCV treatment programs

\begin{tabular}{|c|c|c|c|c|c|c|c|c|c|c|c|}
\hline & \multirow{2}{*}{$\begin{array}{l}\text { Referred for } \\
\text { assessment }\end{array}$} & \multirow{2}{*}{$\begin{array}{c}\text { Treatment } \\
\text { initiated }\end{array}$} & \multirow{2}{*}{ Treatment } & \multirow{2}{*}{$\begin{array}{l}\text { Male } \\
(\%)\end{array}$} & \multirow{2}{*}{$\begin{array}{c}\text { Cirrhosis } \\
(\%)\end{array}$} & \multirow{2}{*}{$\begin{array}{l}\text { PWID } \\
(\%)\end{array}$} & \multirow{2}{*}{ GT $1(\%)$} & \multirow{2}{*}{$\begin{array}{l}\text { GT } 3 \\
(\%)\end{array}$} & \multirow{2}{*}{$\begin{array}{c}\text { Ceased } \\
\text { early }\end{array}$} & \multicolumn{2}{|c|}{ SVR } \\
\hline & & & & & & & & & & ITT & PP \\
\hline Farley et al. ${ }^{[52]}$ & 214 & 90 & IFN RBV & $90(100)$ & $4(6)$ & $70(77)$ & $49(54)$ & $30(33)$ & $17(19)$ & $48 \%$ & $56 \%$ \\
\hline Sabbatani et al. ${ }^{[53]}$ & 127 & 39 & PEG RBV & $38(97)$ & $1 / 12(8)$ & $36(92)$ & $19(49)$ & $20(51)$ & $24(62)$ & $21 \%$ & $40 \%$ \\
\hline Chew et al..$^{[54]}$ & - & 71 & PEG RBV & $71(100)$ & $3 / 59(5)$ & $61(86)$ & $46(65)$ & $9(13)$ & $38(54)$ & $28 \%$ & $59 \%$ \\
\hline Strock et al. ${ }^{[55]}$ & 211 & 86 & $\mathrm{PEG}+/-\mathrm{RBV}$ & - & - & $75(87)$ & - & - & $30(35)$ & $52 \%$ & - \\
\hline Simonovic Babic et al. ${ }^{[56]}$ & 76 & 32 & PEG RBV & $28(88)$ & $5(16)$ & $30(88)$ & $12(38)$ & - & $4(13)$ & $53 \%$ & $63 \%$ \\
\hline Maru et $a l^{[57]}$ & 138 & 68 & PEG RBV & $58(85)$ & $11(68)$ & $46(68)$ & $51(75)$ & $6(9)$ & $21(31)$ & $47 \%$ & $54 \%$ \\
\hline Aspinall et al. ${ }^{[58]}$ & - & 291 & PEG RBV & $261(90)$ & $8(3)$ & $\begin{array}{l}180 / 200 \\
(90)\end{array}$ & $\begin{array}{l}115(40) \\
\text { incl GT4 }\end{array}$ & $160(55)$ & - & $61 \%$ & $83 \%$ \\
\hline Bartlett et al. ${ }^{[59]}$ & 125 & 119 & DAA & $119(100)$ & $14(12)$ & - & $44(37)$ & $72(61)$ & - & $65 \%$ & $97 \%$ \\
\hline Blogg et al. ${ }^{[60]}$ & - & 18 & DAA & - & - & - & - & - & - & $83 \%$ & $100 \%$ \\
\hline Sterling et al. ${ }^{[61]}$ & 220 & 180 & DAA & $80(95)$ & 149 (83) & - & $158(88)$ & $10(6)$ & - & $52 \%$ & $94 \%$ \\
\hline
\end{tabular}

HCV: hepatitis C virus; DAA: direct acting antiviral; GT1: genotype 1; GT3: genotype 3; INF RBV: interferon \& ribavirin; ITT: Intention-to-treat; PEG RBV: pegylated interferon \& ribavirin; PP: per-protocol; SVR: sustained virological response; PWID: people who inject drugs

Treatment for HCV using PEG RBV could be delivered in a manner that was safe and effective, but was resource intensive and only suitable for a small number of prisoners ${ }^{[25]}$, burdened by high rates of adverse effects and treatment discontinuation. The largest prison based PEG RBV study ${ }^{[58]}$ specifically demonstrated that treatment outcomes for therapy delivered to a cohort in both the prison and in the community were not significantly different $(61 \% v$ s. $63 \%, P>0.05)$. SVR rates were lower when a prisoner was transferred between prisons while receiving treatment or when released on treatment. Frequent interprison transfer and early parole therefore present challenges for correctional treatment programs. Treatment rates remain low. As recently as 2015, a survey conducted in 49 of the 50 State Department of Corrections in the US, responsible for the care of $1,348,716$ prisoners, estimated that $<1 \%$ of chronically infected prisoners were receiving treatment at that time $e^{[18]}$.

While modelling demonstrates that HCV DAA treatment is cost effective and efficacious, there are limited real-world data regarding the use of DAAs in correctional facilities worldwide [Table 2]. A recent publication demonstrated HCV micro-elimination within one prison in a jurisdiction of Australia ${ }^{[59]}$. HCV DAA therapy was commenced in 119 prisoners. SVR12 data was available for 66 prisoners at the SVR12 time point and on per protocol analysis, SVR12 was achieved in $97 \%(n=64 / 66)$. Where SVR12 data were not available, prisoners had most commonly already been released. No treatment-related serious adverse outcomes were reported. HCV point prevalence decreased over the study period from $12.6 \%$ to $1.1 \%$. A survey of almost all the US prison authorities in 2015 indicated that 90\% were in contract negotiations to secure HCV DAA therapy for use within their prisons indicating that existing treatment paradigms within correctional facilities are changing and we await further data. Robust data detailing the efficacy of HCV DAA therapy within the prison are needed to demonstrate the contribution that prison treatment programs can make to the elimination agenda.

\section{CONCLUSION}

Concerted efforts to increase HCV treatment rates amongst PWIDs are required to eliminate HCV as a public health threat. Correctional facilities provide ready access to large numbers of PWIDs, a population that is challenging to engage and retain in medical care in the community. The nexus between HCV infection, injecting drug use, and drug-related crime manifests a high prevalence of HCV within the prison.

Treatment as prevention for HCV amongst PWIDs is both efficacious and cost-effective. As injecting drug use is the key driver of $\mathrm{HCV}$ incidence, the benefit of this approach is the rapid reduction in community $\mathrm{HCV}$ prevalence and incidence, achieved by treating a small proportion of current PWIDs. There is clear evidence of these benefits as supported by multiple modelling studies. Traditional approaches have had limited success improving the cascade of care for HCV among PWIDs ${ }^{[62]}$. Modelling studies of the impact of TAsP at the 
population level support the development and implementation of novel public health platforms, including within the prison system. Such prison-based HCV treatment programs will facilitate the engagement and treatment of PWIDs, a key role in promoting the achievement of the WHO elimination goals by 2030.

Multiple barriers within the prison impede HCV management in prisons. Future studies should evaluate models of care that overcome these barriers. It will be important to evaluate the implementation of enhanced opt-out screening programs in all correctional facilities; the benefit of point of care diagnosis and referral on prison reception for reducing the time for diagnosis to treatment; and the benefit of peer-led prisoner education programs to promote uptake of screening and treatment. Historically HCV therapy for prisoners has been impeded by delays in transfer for specialist assessment, frequent prisoner transfer interrupting treatment and the need for frequent transfer to tertiary centres for monitoring and diagnostics. The development of jurisdiction-wide, comprehensive "in-reach" hepatitis treatment program could overcome these barriers and provide HCV care locally at each prison site, minimising the need for transfers.

In conclusion, prisoner hepatitis treatment programs should be included in HCV elimination paradigms to maximise the TAsP effect. Novel treatment programs are needed to access and scale up treatment in these marginalised populations.

\section{DECLARATIONS}

\section{Authors' contributions}

Both authors contributed equally to the research and writing of the manuscript.

\section{Availability of data and materials}

Not applicable.

\section{Financial support and sponsorship}

None.

\section{Conflicts of interest}

All authors declared that there are no conflicts of interest.

\section{Ethical approval and consent to participate}

Not applicable.

\section{Consent for publication}

Not applicable.

\section{Copyright}

(c) The Author(s) 2018.

\section{REFERENCES}

1. Blach S, Zeuzem S, Manns M, Altraif I, Duberg AS, et al. Global prevalence and genotype distribution of hepatitis C virus infection in 2015: a modelling study. Lancet Gastroenterol Hepatol 2017;2:161-76.

2. Dore GJ, Freeman AJ, Law M, Kaldor JM. Is severe liver disease a common outcome for people with chronic hepatitis C? J Gastroenterol Hepatol 2002;17:423-30.

3. Limburg W; European Monitoring Centre for Drugs and Drug Addiction. Natural history, treatment and prevention of hepatitis C in injecting drug users: an overview. Available from: http://www.emcdda.europa.eu/system/files/publications/344/EMCDDAmonograph7en_59382.pdf. [Last accessed on 12 Oct 2018]

4. Wong RJ, Aguilar M, Cheung R, Perumpail RB, Harrison SA, et al. Nonalcoholic steatohepatitis is the second leading etiology of liver disease among adults awaiting liver transplantation in the United States. Gastroenterology 2015;148:547-55.

5. Lozano R, Naghavi M, Foreman K, Lim S, Shibuya K, et al. Global and regional mortality from 235 causes of death for 20 age groups in 
1990 and 2010: a systematic analysis for the Global Burden of Disease Study 2010. Lancet 2012;380:2095-128.

6. Stanaway JD, Flaxman AD, Naghavi M, Fitzmaurice C, Vos T, et al. The global burden of viral hepatitis from 1990 to 2013: findings from the Global Burden of Disease Study 2013. Lancet 2016;388:1081-8.

7. de Martel C, Maucort-Boulch D, Plummer M, Franceschi S. World-wide relative contribution of hepatitis B and C viruses in hepatocellular carcinoma. Hepatology 2015;62:1190-200.

8. Okanoue T, Sakamoto S, Itoh Y, Minami M, Yasui K, et al. Side effects of high-dose interferon therapy for chronic hepatitis C. J Hepatol 1996;25:283-91.

9. WHO. Combating hepatitis B and C to reach elimination by 2030: advocacy brief. Available from: https://www.who.int/hepatitis/ publications/hep-elimination-by-2030-brief/en/. [Last accessed on 9 Oct 2018]

10. Nelson PK, Mathers BM, Cowie B, Hagan H, Des Jarlais D, et al. Global epidemiology of hepatitis B and hepatitis C in people who inject drugs: results of systematic reviews. Lancet 2011;378:571-83.

11. Alter MJ. Epidemiology of hepatitis C virus infection. World J Gastroenterol 2007;13:2436-41.

12. Scott N, Doyle JS, Wilson DP, Wade A, Howell J, et al. Reaching hepatitis C virus elimination targets requires health system interventions to enhance the care cascade. Int J Drug Policy 2017;47:107-16.

13. Walmsley R; Internation Centre for Prison Studies. World prison population list (tenth edition). Available from: https://www.prisonstudies. org/sites/default/files/resources/downloads/wppl_10.pdf. [Last accessed on 9 Oct 2018]

14. Wagner P, Rabuy B; Prison Policy Initiative. Mass incarceration: the whole pie 2016. Available from: https://www.prisonpolicy.org/reports/ pie2018.html. [Last accessed on 9 Oct 2018]

15. Dolan K, Wirtz AL, Moazen B, Ndeffo-Mbah M, Galvani A, et al. Global burden of HIV, viral hepatitis, and tuberculosis in prisoners and detainees. Lancet 2016;388:1089-102.

16. Murphy EL, Bryzman SM, Glynn SA, Ameti DI, Thomson RA, et al. Risk factors for hepatitis C virus infection in United States blood donors. Hepatology 2000;31:756-62.

17. Jürgens R, Nowak M, Day M. HIV and incarceration: prisons and detention. J Int AIDS Soc 2011;14:26.

18. Beckman AL, Bilinski A, Boyko R, Camp GM, Wall AT, et al. New hepatitis C drugs are very costly and unavailable to many state prisoners. Health Aff (Millwood) 2016;35:1893-901.

19. DeBeck K, Cheng T, Montaner JS, Beyrer C, Elliott R, et al. HIV and the criminalisation of drug use among people who inject drugs: a systematic review. Lancet HIV 2017;4:e357-74.

20. Larney S, Kopinski H, Beckwith CG, Zaller ND, Jarlais DD, et al. Incidence and prevalence of hepatitis C in prisons and other closed settings: results of a systematic review and meta-analysis. Hepatology 2013;58:1215-24.

21. Boonwaat L, Haber PS, Levy MH, Lloyd AR. Establishment of a successful assessment and treatment service for Australian prison inmates with chronic hepatitis C. Med J Aust 2010;192:496-500.

22. Lloyd AR, Clegg J, Lange J, Stevenson A, Post JJ, et al. Safety and effectiveness of a nurse-led outreach program for assessment and treatment of chronic hepatitis C in the custodial setting. Clin Infect Dis 2013;56:1078-84.

23. WHO. Prisons and health. Available from: https://www.euro.who.int/_data/assets/pdf_file/0005/249188/Prisons-and-Health.pdf. [Last accessed on 9 Oct 2018]

24. ECDC. Technical report: surveillance and prevention of hepatitis B and C in Europe. Available from: https://ecdc.europa.eu/sites/portal/ files/media/en/publications/Publications/101012_TER_HepBandC_survey.pdf. [Last accessed on 9 Oct 2018]

25. Spaulding AC, Weinbaum CM, Lau DT, Sterling R, Seeff LB, et al. A framework for management of hepatitis C in prisons. Ann Intern Med 2006;144:762-9.

26. Imperial JC. Chronic hepatitis $\mathrm{C}$ in the state prison system: insights into the problems and possible solutions. Expert Rev Gastroenterol Hepatol 2010;4:355-64.

27. De P, Connor N, Bouchard F, Sutherland D. HIV and hepatitis C virus testing and seropositivity rates in Canadian federal penitentiaries: a critical opportunity for care and prevention. Can J Infect Dis Med Microbiol 2004;15:221-5.

28. Kirwan P, Evans B; Sentinel Surveillance of Hepatitis Testing Study Group, Brant L. Hepatitis C and B testing in English prisons is low but increasing. J Public Health (Oxf) 2011;33:197-204.

29. Rich JD, Beckwith CG, Macmadu A, Marshall BDL, Brinkley-Rubinstein L, et al. Clinical care of incarcerated people with HIV, viral hepatitis, or tuberculosis. Lancet 2016;388:1103-14.

30. Post JJ, Arain A, Lloyd AR. Enhancing assessment and treatment of hepatitis C in the custodial setting. Clin Infect Dis 2013; doi: 10.1093/ $\mathrm{cid} / \mathrm{cit} 265$.

31. Khaw FM, Stobbart L, Murtagh MJ. 'I just keep thinking I haven't got it because I'm not yellow': a qualitative study of the factors that influence the uptake of hepatitis C testing by prisoners. BMC Public Health 2007;7:98.

32. Hickman M, McDonald T, Judd A, Nichols T, Hope V, et al. Increasing the uptake of hepatitis $\mathrm{C}$ virus testing among injecting drug users in specialist drug treatment and prison settings by using dried blood spots for diagnostic testing: a cluster randomized controlled trial. J Viral Hepat 2008;15:250-4.

33. Humphreys C, Railton C, O’Moore É, Lombard M, Newton A. An audit of hepatitis C service provision in a representative sample of prisons in England. J Public Health (Oxf) 2015;37:151-6.

34. Hochstatter KR, Stockman LJ, Holzmacher R, Greer J, Seal DW, et al. The continuum of hepatitis C care for criminal justice involved adults in the DAA era: a retrospective cohort study demonstrating limited treatment uptake and inconsistent linkage to community-based care. Health Justice 2017;5:10.

35. Mina MM, Herawati L, Butler T, Lloyd A. Hepatitis C in Australian prisons: a national needs assessment. Int J Prison Health 2016;12:3-16.

36. Yap L, Carruthers S, Thompson S, Cheng W, Jones J, et al. A descriptive model of patient readiness, motivators, and hepatitis C treatment uptake among Australian prisoners. PLoS One 2014; doi: 10.1371/journal.pone.0087564.

37. James DJ, Glaze LE; Bureau of Justice Statistics Washington. Mental health problems of prison and jail inmates. Available from: https:// 
www.bjs.gov/content/pub/pdf/mhppji.pdf. [Last accessed on 9 Oct 2018]

38. Kramer JR, Kanwal F, Richardson P, Mei M, El-Serag HB. Gaps in the achievement of effectiveness of HCV treatment in national VA practice. J Hepatol 2012;56:320-5.

39. Rosenthal ES, Graham CS. Price and affordability of direct-acting antiviral regimens for hepatitis C virus in the United States. Infect Agent Cancer 2016;11:24.

40. Leclerc P, Roy É, Morissette C. Le volet montréalais du Réseau SurvUDI: Volume 2: données au 30 juin 2008: agence de la santé et des services sociaux de Montréal, direction de santé publique. Available from: http://collections.banq.qc.ca/ark:/52327/bs1983220. [Last accessed on 12 Oct 2018]

41. Razavi H, Waked I, Sarrazin C, Myers RP, Idilman R, et al. The present and future disease burden of hepatitis C virus (HCV) infection with today's treatment paradigm. J Viral Hepat 2014;21:34-59.

42. Browne AJ, Varcoe CM, Wong ST, Smye VL, Lavoie J, et al. Closing the health equity gap: evidence-based strategies for primary health care organizations. Int J Equity Health 2012;11:59.

43. Hellard M, Sacks-Davis R, Doyle J. Hepatitis C elimination by 2030 through treatment and prevention: think global, act in local networks. J Epidemiol Community Health 2016;70:1151-4.

44. Rolls DA, Sacks-Davis R, Jenkinson R, McBryde E, Pattison P, et al. Hepatitis C transmission and treatment in contact networks of people who inject drugs. PloS One 2013; doi: 10.1371/journal.pone.0078286.

45. Olafsson S, Tyrfingsson T, Runarsdottir V, Bergmann OM, Hansdottir I, et al. Treatment as prevention for hepatitis C (TraP Hep C) - a nationwide elimination programme in Iceland using direct-acting antiviral agents. J Intern Med 2018;283:500-7.

46. Cousien A, Leclerc P, Morissette C, Bruneau J, Roy É, et al. The need for treatment scale-up to impact HCV transmission in people who inject drugs in Montréal, Canada: a modelling study. BMC Infect Dis 2017;17:162.

47. Zelenev A, Li J, Mazhnaya A, Basu S, Altice FL. Hepatitis C virus treatment as prevention in an extended network of people who inject drugs in the USA: a modelling study. Lancet Infect Dis 2018;18:215-24.

48. Martin NK, Vickerman P, Dore GJ, Grebely J, Miners A, et al. Prioritization of HCV treatment in the direct-acting antiviral era: an economic evaluation. J Hepatol 2016;65:17-25.

49. Barua S, Greenwald R, Grebely J, Dore GJ, Swan T, et al. Restrictions for medicaid reimbursement of sofosbuvir for the treatment of hepatitis C virus infection in the United States. Ann Intern Med 2015;163:215-23.

50. Stone J, Martin NK, Hickman M, Hutchinson SJ, Aspinall E, et al. Modelling the impact of incarceration and prison-based hepatitis C virus (HCV) treatment on HCV transmission among people who inject drugs in Scotland. Addiction 2017;112:1302-14.

51. Martin NK, Vickerman P, Brew IF, Williamson J, Miners A, et al. Is increased hepatitis C virus case-finding combined with current or 8-week to 12-week direct-acting antiviral therapy cost-effective in UK prisons? A prevention benefit analysis. Hepatology 2016;63:1796808.

52. Farley JD, Wong VK, Chung HV, Lim E, Walters G, et al. Treatment of chronic hepatitis C in Canadian prison inmates. Can J Gastroenterol 2005;19:153-6.

53. Sabbatani S, Giuliani R, Manfredi R. Combined pegylated interferon and ribavirin for the management of chronic hepatitis $\mathrm{C}$ in a prison setting. Braz J Infect Dis 2006;10:274-8.

54. Chew KW, Allen SA, Taylor LE, Rich JD, Feller E. Treatment outcomes with pegylated interferon and ribavirin for male prisoners with chronic hepatitis C. J Clin Gastroenterol 2009;43:686-91.

55. Strock P, Mossong J, Hawotte K, Arendt V. Access to treatment of hepatitis C in prison inmates. Dig Dis Sci 2009;54:1325-30.

56. Simonović Babić J, Bojović K, Delić D, Katanić N, Mitrović N, et al. Antiviral treatment of hepatitis C in Serbian prison setting: medical treatment outcomes and patients' adherence. Med Pregl 2016;69:85-91.

57. Maru DS, Bruce RD, Basu S, Altice FL. Clinical outcomes of hepatitis C treatment in a prison setting: feasibility and effectiveness for challenging treatment populations. Clin Infect Dis 2008;47:952-61.

58. Aspinall EJ, Mitchell W, Schofield J, Cairns A, Lamond S, et al. A matched comparison study of hepatitis C treatment outcomes in the prison and community setting, and an analysis of the impact of prison release or transfer during therapy. J Viral Hepat 2016;23:1009-16.

59. Bartlett SR, Fox P, Cabatingan H, Jaros A, Gorton C, et al. Demonstration of near-elimination of hepatitis C virus among a prison population: the Lotus Glen Correctional Centre hepatitis C treatment project. Clin Infect Dis 2018;67:460-3.

60. Blogg J, Wood J, McGrath C, Lobo C. Eradicating hepatitis C from the New South Wales prison system. Med J Aust 2018;208:276.

61. Sterling RK, Cherian R, Lewis S, Genther K, Driscoll C, et al. Treatment of HCV in the department of corrections in the era of ora medications. J Correct Health Care 2018;24:127-36.

62. Doab A, Treloar C, Dore GJ. Knowledge and attitudes about treatment for hepatitis $\mathrm{C}$ virus infection and barriers to treatment among current injection drug users in Australia. Clin Infect Dis 2005;40:S313-20. 